\title{
Propensity-matched comparison of outcomes and cost after macroscopic and microscopic lumbar discectomy using a national longitudinal database
}

\author{
*Arjun Vivek Pendharkar, MD, Paymon Garakani Rezaii, MS, Allen Lin Ho, MD, \\ Eric Scott Sussman, MD, David Arnold Purger, MD, PhD, Anand Veeravagu, MD, \\ John Kevin Ratliff, MD, and Atman Mukesh Desai, MD \\ Department of Neurosurgery, Stanford University, Stanford, California
}

\begin{abstract}
OBJECTIVE There has been considerable debate about the utility of the operating microscope in lumbar discectomy and its effect on outcomes and cost.

METHODS A commercially available longitudinal database was used to identify patients undergoing discectomy with or without use of a microscope between 2007 and 2015. Propensity matching was performed to normalize differences between demographics and comorbidities in the 2 cohorts. Outcomes, complications, and cost were subsequently analyzed using bivariate analysis.
\end{abstract}

RESULTS A total of 42,025 patients were identified for the "macroscopic" group, while 11,172 patients were identified for the "microscopic" group. For the propensity-matched analysis, the 11,172 patients in the microscopic discectomy group were compared with a group of 22,340 matched patients who underwent macroscopic discectomy. There were no significant differences in postoperative complications between the groups other than a higher proportion of deep vein thrombosis (DVT) in the macroscopic discectomy cohort versus the microscopic discectomy group $(0.4 \%$ vs $0.2 \%$, matched OR $0.48[95 \% \mathrm{Cl} 0.26-0.82], p=0.0045)$. Length of stay was significantly longer in the macroscopic group compared to the microscopic group (mean 2.13 vs 1.83 days, $p<0.0001$ ). Macroscopic discectomy patients had a higher rate of revision surgery when compared to microscopic discectomy patients (OR 0.92 [95\% Cl 0.84-1.00], $p=0.0366$ ). Hospital charges were higher in the macroscopic discectomy group (mean $\$ 19,490$ vs $\$ 14,921, p<0.0001$ ).

CONCLUSIONS The present study suggests that the use of the operating microscope in lumbar discectomy is associated with decreased length of stay, lower DVT rate, lower reoperation rate, and decreased overall hospital costs.

https://thejns.org/doi/abs/10.3171/2018.1.FOCUS17791

KEYWORDS microscope; lumbar disc herniation; discectomy; cost; outcome; back pain; sciatica

$\mathrm{L}$ UMBAR discectomy is the most common spinal procedure performed in the United States. ${ }^{1}$ Back pain and sciatica, in general, represent a significant burden on the US health care system. ${ }^{8}$ The use of the operating microscope for discectomy was first introduced by Yaşargil and Caspar in Switzerland and Germany, respectively, $2,8,16$ and later popularized in the United States by Williams. ${ }^{15}$

Since that time there has been considerable debate about the utility of the operating microscope and its effect on outcomes and cost in lumbar discectomy. There are several theoretical advantages, including improved visualization and reduced need for bony/ligamentous disruption potentially leading to less postoperative pain, smaller incisions, earlier discharge, and even possibly quicker return to work. ${ }^{6}$ However, the evidence in support of this has thus far been limited and often contradictory. ${ }^{3-5,7,9-11}$

We utilized a longitudinal national database to identify

ABBREVIATIONS CPT $=$ Current Procedural Terminology; $\mathrm{DVT}=$ deep vein thrombosis .

SUBMITTED December 28, 2017. ACCEPTED January 24, 2018.

INCLUDE WHEN CITING DOI: 10.3171/2018.1.FOCUS17791.

* A.V.P. and P.G.R. contributed equally to this work. 
patients undergoing discectomy with or without usage of the operative microscope and examined the postoperative outcomes and costs in the 2 propensity-matched cohorts.

\section{Methods \\ Database}

The Thomson Reuters MarketScan Commercial Claims and Encounters Database and the MarketScan Medicare Supplemental and Coordination of Benefits Database (Truven Health Analytics Inc.) were used to find patient-specific clinical utilization, expenditure, and enrollment data for the period of 2007-2015. The MarketScan Commercial Database includes hospital claims, physician claims, surgeon claims, and laboratory claims from large US employers and health plans for employees, spouses, and dependents. The MarketScan Medicare Supplemental Database includes claims from patients with Medicare supplemental coverage, as well as their dependents. Both databases have been thoroughly examined and validated for completeness, accuracy, and reliability. All data from these databases are de-identified, and thus this study is exempt from IRB approval in accordance with the Health Insurance Portability and Accountability Act of 1996.

\section{Patient Selection}

Current Procedural Terminology (CPT) code 63030 for single-level lumbar discectomy was used to define the initial cohort, which was further refined by selecting individuals with a minimum of 1 year of continuous enrollment (Fig. 1). These patients were then stratified into 2 groups: the microscopic discectomy group (CPT 63030 with 69990), and the macroscopic discectomy group (CPT 63030 without 69990). A total of 42,025 patients were identified for the macroscopic group, while 11,172 patients were identified for the microscopic group.

\section{Covariates and Matching}

To minimize baseline differences between treatment groups, propensity-score matching was employed, balancing the groups on baseline comorbidities and procedure characteristics. Specifically, a greedy matching algorithm (without replacements) was used, with the caliper set at $20 \%$ of the standard deviation of the logit of the propensity score. Matching covariates were chosen based on clinician judgment and are found in Tables 1 and 2. Macroscopic/ microscopic matching $(2: 1)$ was performed, which resulted in all matched covariate standardized differences of less than 0.05. Surgeon identifier codes were used to determine the number of operations performed by neurosurgeons and orthopedic surgeons. Outcomes were compared between groups using bivariate analysis.

\section{Outcomes Analyzed}

Outcomes of interest included length of stay, postoperative complications within 30 days, readmissions for any cause within 30 days, reoperations until the end of available data, and discharge status. Length of stay is reported as number of nights in the MarketScan database and thus in this paper as well. Reoperation procedures were defined

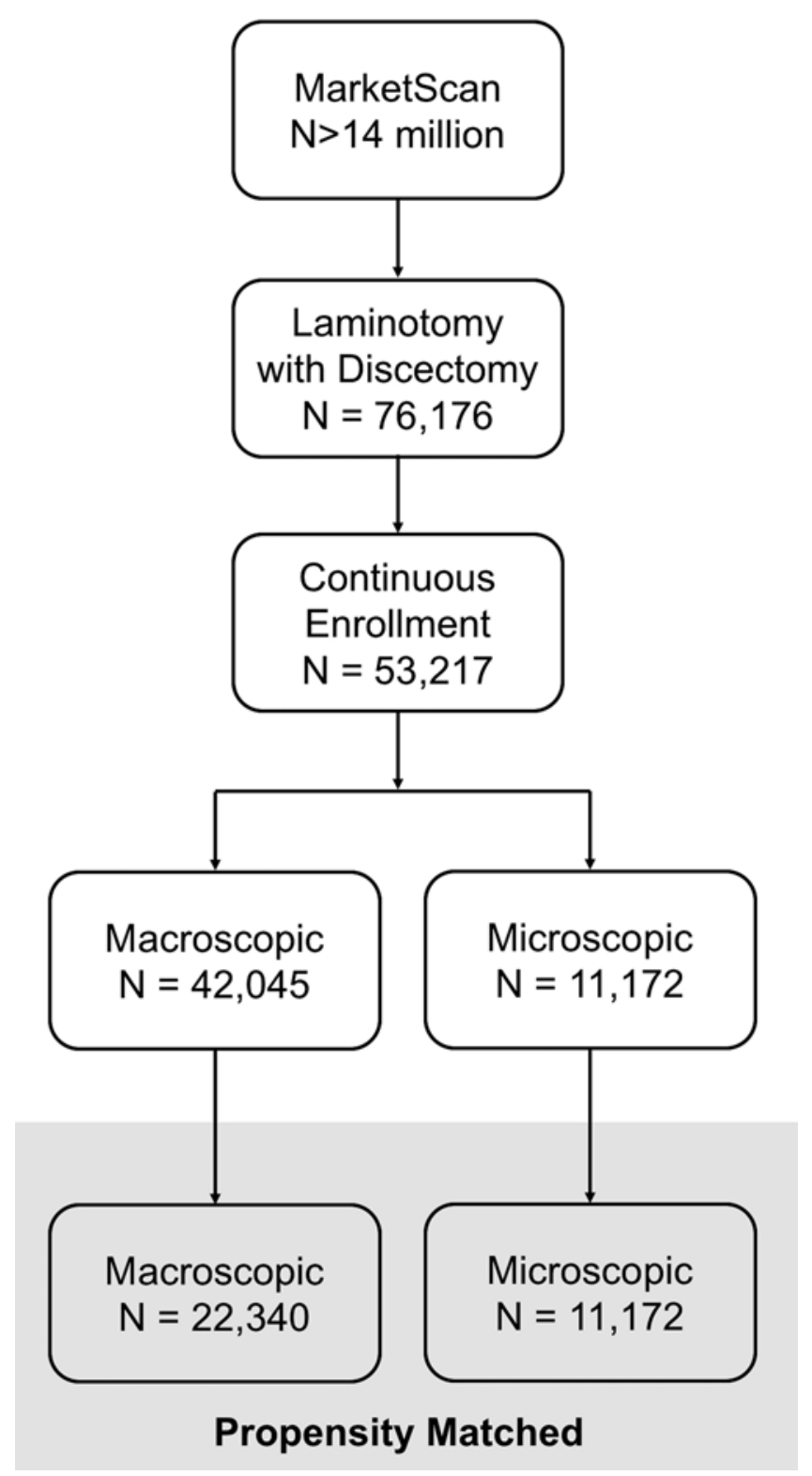

FIG. 1. Flowchart outlining patient inclusion criteria using the MarketScan database and CPT codes for laminotomy with discectomy (CPT 63030) with or without concurrent usage of microscope (CPT 69990).

by CPT codes 63042, 63044, 63047, 22633, and 22612 . Complications were defined as any complication listed in Table 3 without the same ICD-9 diagnosis within 180 days from the initial index procedure (lumbar discectomy). Discharge statuses were reclassified as either "sent home" or "other," the latter primarily consisting of "transferred" statuses.

\section{Data Analysis}

Statistical analyses were conducted on all outcomes using 2-tailed tests with a significance level of 0.05. Fisher exact tests were used for categorical variables, while Student t-tests (Satterthwaite test for statistical significance) were used for continuous variables. The Holm-Bonferroni 
correction method for multiple comparisons was used to properly assess postoperative complications. Statistical analysis and propensity matching were performed in $\mathrm{R}$ Studio version 1.0.153.

\section{Results \\ Patient Populations}

A total of 53,217 patients were identified as having undergone a lumbar discectomy with continuous enrollment in the longitudinal database for at least 1 year (Fig. 1). Of these patients, 11,172 were included in the "microscopic" discectomy cohort based on co-occurrence of CPT code 69990, while the remaining 42,045 patients were included in the "macroscopic" group (without CPT 69990). Importantly, all patients with codes for lumbar instrumented fusion were excluded from this study. Using surgeon identifier codes, we found no significant difference in rates of microscope use between neurosurgeons and orthopedists (37\% vs $39.5 \%)$.

\section{Propensity Matching}

The demographics and comorbidities of the 2 populations are outlined in Table 1 . There were significant differences in patient sex, tobacco usage, obesity, diabetes, chronic obstructive pulmonary disease, hypertension, history of myocardial infarction, and presence of spinal stenosis or spondylosis. There were also a significantly lower proportion of Medicare beneficiaries in the microscopic cohort and a regional predominance for more microscopic discectomy in the West. To more accurately study the use of a microscope during discectomy and its effect on outcome, we applied a propensity-matching algorithm, which produced the 2 groups outlined in Table 2 (22,340 patients in the macroscopic group and 11,172 in the microscopic group). After propensity matching, the 2 groups were not found to be statistically different in any of the demographics or comorbidities except for sex, with the microscopic discectomy group having a slightly smaller proportion of male patients (OR 0.94 [95\% CI 0.90-0.99], $\mathrm{p}=0.0143$ ).

\section{Thirty-Day Perioperative Complications}

We first evaluated whether the use of a microscope during discectomy resulted in any change in postoperative outcome within 30 days of the index procedure (Table $3)$. There was no significant difference in the propensitymatched cohorts' rates of wound infection, dehiscence, hematoma, or dural tear. Similarly, there were no significant differences in rates of pulmonary or neurological complications. There was a significantly higher proportion

TABLE 1. Unmatched patient demographics and comorbidities

\begin{tabular}{|c|c|c|c|c|}
\hline \multirow[b]{2}{*}{ Variable } & \multicolumn{2}{|c|}{ Discectomy Group } & \multirow[b]{2}{*}{ OR $(95 \% \mathrm{Cl})$} & \multirow[b]{2}{*}{$p$ Value } \\
\hline & Macroscopic & Microscopic & & \\
\hline No. of patients & 42,045 & 11,172 & & \\
\hline Age, mean (SD) & $52.9(14.6)$ & $49.6(13.7)$ & & 0.5686 \\
\hline Male & $20,509(48.8)$ & $5139(46)$ & $0.89(0.86-0.93)$ & $<0.0001$ \\
\hline Tobacco & $5823(13.8)$ & $1711(15.3)$ & $1.12(1.06-1.19)$ & $<0.0001$ \\
\hline Obesity & $2289(5.4)$ & $704(6.3)$ & $1.16(1.06-1.27)$ & 0.0006 \\
\hline Diabetes & $4383(10.4)$ & $1060(9.5)$ & $0.90(0.83-0.97)$ & 0.0035 \\
\hline $\mathrm{CHF}$ & $254(0.60)$ & $54(0.5)$ & $0.80(0.58-1.08)$ & 0.1409 \\
\hline COPD & $2460(5.9)$ & $728(6.5)$ & $1.12(1.03-1.22)$ & 0.0093 \\
\hline Alcohol & $62(0.1)$ & $15(0.1)$ & $0.91(0.48-1.62)$ & 0.8886 \\
\hline Hypertension & $13,607(32.4)$ & $3436(30.8)$ & $0.93(0.89-0.97)$ & 0.0012 \\
\hline Other neurologic disease & $595(1.4)$ & $131(1.2)$ & $0.83(0.68-1.00)$ & 0.0538 \\
\hline Deficiency anemia & $1118(2.8)$ & $278(2.5)$ & $0.88(0.77-1.00)$ & 0.0550 \\
\hline Medicare & $8610(20.5)$ & $1282(11.5)$ & $0.50(0.47-0.50)$ & $<0.0001$ \\
\hline Degenerative disc disease & $12,989(30.9)$ & $3377(30.2)$ & $0.97(0.93-1.01)$ & 0.1772 \\
\hline Osteoporosis & $425(1.0)$ & $109(1.0)$ & $0.96(0.77-1.19)$ & 0.7895 \\
\hline $\mathrm{Ml}$ & $674(1.6)$ & $146(1.3)$ & $0.81(0.67-0.97)$ & 0.0246 \\
\hline Spinal stenosis & $17,736(42.2)$ & $3465(31)$ & $0.62(0.59-0.64)$ & $<0.0001$ \\
\hline Spondylosis & 7470 (17.8) & $1553(13.9)$ & $0.75(0.70-0.79)$ & $<0.0001$ \\
\hline \multicolumn{5}{|l|}{ Region } \\
\hline Northeast & 7633 (18.2) & $1227(11)$ & $0.56(0.52-0.59)$ & $<0.0001$ \\
\hline North Central & $11,253(26.8)$ & $2903(26)$ & $0.96(0.92-1.00)$ & 0.0989 \\
\hline South & $15,139(36.0)$ & $3893(34.8)$ & $0.95(0.91-0.99)$ & 0.0228 \\
\hline West & 7304 (17.4) & $2922(26.2)$ & $1.68(1.60-1.77)$ & $<0.0001$ \\
\hline Unknown & $716(1.7)$ & $227(2.0)$ & $1.20(1.03-1.39)$ & 0.0214 \\
\hline
\end{tabular}

$\mathrm{CHF}=$ congestive heart failure; $\mathrm{COPD}=$ chronic obstructive pulmonary disease $; \mathrm{MI}=$ myocardial infarction.

Values are number of patients (\%) unless otherwise indicated. 
TABLE 2. Matched patient demographics and comorbidities

\begin{tabular}{|c|c|c|c|c|}
\hline \multirow[b]{2}{*}{ Variable } & \multicolumn{2}{|c|}{ Discectomy Group } & \multirow[b]{2}{*}{ OR $(95 \% \mathrm{Cl})$} & \multirow[b]{2}{*}{$\mathrm{p}$ Value } \\
\hline & Macroscopic & Microscopic & & \\
\hline No. of patients & 22,340 & 11,172 & & \\
\hline Age, mean (SD) & $49.7(13.7)$ & $49.6(13.7)$ & & 0.5686 \\
\hline Male & $10,593(47.4)$ & $5139(46)$ & $0.94(0.90-0.99)$ & 0.0143 \\
\hline Tobacco & $3347(15.0)$ & $1711(15.3)$ & $1.03(0.96-1.09)$ & 0.4278 \\
\hline Obesity & $1376(6.2)$ & 704 (6.3) & $1.02(0.93-1.13)$ & 0.6141 \\
\hline Diabetes & $2136(9.6)$ & $1060(9.5)$ & $0.99(0.92-1.07)$ & 0.8436 \\
\hline $\mathrm{CHF}$ & $103(0.5)$ & $54(0.5)$ & $1.05(0.74-1.47)$ & 0.7992 \\
\hline COPD & $1405(6.3)$ & $728(6.5)$ & $1.04(0.95-1.14)$ & 0.4198 \\
\hline Alcohol & $34(0.2)$ & $15(0.1)$ & $0.88(0.45-1.66)$ & 0.7630 \\
\hline Hypertension & $6774(30.3)$ & $3436(30.8)$ & $1.02(0.97-1.07)$ & 0.4205 \\
\hline Other neurologic disease & $253(1.1)$ & $131(1.2)$ & $1.04(0.83-1.29)$ & 0.7442 \\
\hline Deficiency anemia & $577(2.6)$ & $278(2.5)$ & $0.96(0.83-1.11)$ & 0.6329 \\
\hline Medicare & 2498 (11.2) & $1282(11.5)$ & $1.03(0.96-1.11)$ & 0.4310 \\
\hline Degenerative disc disease & $6774(30.3)$ & $3377(30.2)$ & $1.00(0.95-1.05)$ & 0.8599 \\
\hline Osteoporosis & $203(0.9)$ & $109(1.0)$ & $1.07(0.84-1.36)$ & 0.5467 \\
\hline Ml & $325(1.5)$ & $146(1.3)$ & $0.90(0.73-1.10)$ & 0.3013 \\
\hline Spinal stenosis & $6778(30.3)$ & 3465 (31) & $1.03(0.98-1.08)$ & 0.2085 \\
\hline Spondylosis & 3086 (13.8) & $1553(13.9)$ & $1.01(0.94-1.08)$ & 0.8274 \\
\hline \multicolumn{5}{|l|}{ Region } \\
\hline Northeast & 2537 (11.4) & 1227 (11) & $0.96(0.90-1.04)$ & 0.3129 \\
\hline North Central & $5880(26.3)$ & $2903(26)$ & $0.98(0.93-1.04)$ & 0.5186 \\
\hline South & 8031 (35.9) & $3893(34.8)$ & $0.95(0.91-1.00)$ & 0.0472 \\
\hline West & $5452(24.4)$ & $2922(26.2)$ & $1.10(1.04-1.16)$ & 0.0005 \\
\hline Unknown & $440(2.0)$ & $227(2.0)$ & $1.03(0.87-1.22)$ & 0.7089 \\
\hline
\end{tabular}

Values are number of patients (\%) unless otherwise indicated.

of patients with deep vein thrombosis (DVT) in the macroscopic cohort versus the microscopic discectomy group ( $0.4 \%$ vs $0.2 \%$, matched OR 0.48 [95\% CI $0.26-0.82$ ], p $=0.0045)$.

\section{Postoperative Outcomes}

Several postoperative outcomes differed between the macroscopic and microscopic discectomy groups (Table 4). The mean length of stay was significantly longer in the macroscopic discectomy group than in the microscopic discectomy group (2.13 days vs 1.83 days, $\mathrm{p}<0.0001)$. There was no significant difference in readmission rates, but the rate of revision surgery was significantly higher in the macroscopic discectomy group than in the microscopic discectomy group (OR 0.92 [95\% CI 0.84-1.00], $\mathrm{p}=$ 0.0366). Microscopic discectomy patients were also more likely to be discharged home (OR 1.50 [95\% CI 1.39-1.61], $\mathrm{p}<0.0001)$. Payments also differed significantly. Hospital charges were significantly higher in the macroscopic group (median $\$ 19,490$ vs $\$ 14,921, \mathrm{p}<0.0001$ ), but there was no statistically significant difference in physician payments.

\section{Discussion}

The literature regarding utility of the operating mi- croscope in lumbar discectomy has been controversial. In a prospective single-surgeon series of 114 consecutive patients treated with or without microscope assistance, Türeyen found no difference in hospital stay or overall outcome with 1 year follow-up..$^{14} \mathrm{He}$ did, however, report a difference in incision length and operative time as well as earlier return to work/normal life and less dependence on narcotic analgesia in the microdiscectomy group. In contrast, Katayama et al. reported no differences in analgesic use but did find a shorter hospital stay for patients undergoing microscopic discectomy. ${ }^{7}$ Schmid et al. retrospectively analyzed 500 consecutive cases and reported no difference in clinical outcome or complications but found a shorter length of stay in the microscopic discectomy cohort. ${ }^{12}$ One concern with small clinical series is that they may lack the statistical power to reveal significant differences and so Murphy et al. queried the ACS-NSQIP (American College of Surgeons National Surgical Quality Improvement Program) to review 23,583 patients. ${ }^{10} \mathrm{In}$ their multivariate analysis, microscopic discectomy did not differ significantly in complication rate, dural tear, return to the operating room, or readmission. There was a significantly longer operative time associated with microscope usage.

Our findings with the MarketScan database in a cohort of propensity-matched patients confirm previous reports 
TABLE 3. Thirty-day postoperative complications

\begin{tabular}{|c|c|c|c|c|c|}
\hline \multirow[b]{2}{*}{ Variable } & \multicolumn{2}{|c|}{ Discectomy Group } & \multirow{2}{*}{$\begin{array}{l}\text { Matched OR } \\
(95 \% \mathrm{Cl})\end{array}$} & \multicolumn{2}{|c|}{ Matched $p$ Value } \\
\hline & Macroscopic & Microscopic & & Uncorr & Corr \\
\hline Wound infection & $208(0.9)$ & $101(0.9)$ & $0.93(0.71-1.22)$ & 0.6446 & 1.0000 \\
\hline Wound dehiscence & $51(0.2)$ & $35(0.3)$ & $1.24(0.75-2.04)$ & 0.3848 & 1.0000 \\
\hline Hematoma & $67(0.3)$ & $36(0.3)$ & $1.02(0.63-1.61)$ & 1.0000 & 1.0000 \\
\hline Other wound complication & $10(<0.1)$ & $12(0.1)$ & $2.50(0.89-7.29)$ & 0.0759 & 0.9871 \\
\hline Delirium & $6(<0.1)$ & $3(<0.1)$ & $1.00(0.16-4.68)$ & 1.0000 & 1.0000 \\
\hline Chronic pain & $49(0.2)$ & $27(0.2)$ & $0.89(0.51-1.53)$ & 0.7017 & 1.0000 \\
\hline Pulmonary embolism & $58(0.3)$ & $25(0.2)$ & $0.69(0.38-1.20)$ & 0.2046 & 1.0000 \\
\hline DVT & $79(0.4)$ & $24(0.2)$ & $0.48(0.26-0.82)$ & 0.0045 & 0.0672 \\
\hline Any thromboembolism & $68(0.3)$ & $21(0.2)$ & $0.47(0.24-0.84)$ & 0.0090 & 0.1262 \\
\hline Pulmonary complication & $25(0.1)$ & $16(0.1)$ & $1.24(0.57-2.59)$ & 0.5861 & 1.0000 \\
\hline Neurologic complication & $114(0.5)$ & $61(0.5)$ & $0.93(0.64-1.34)$ & 0.7218 & 1.0000 \\
\hline Dysrhythmia & $4(<0.1)$ & $4(<0.1)$ & $2.00(0.37-10.74)$ & 0.4537 & 1.0000 \\
\hline Dysphagia & $5(<0.1)$ & $1(<0.1)$ & $0.40(0.01-3.57)$ & 0.6708 & 1.0000 \\
\hline Dural tear & $49(0.2)$ & $15(0.1)$ & $0.70(0.36-1.28)$ & 0.2655 & 1.0000 \\
\hline Any complication & $450(2.0)$ & $199(1.8)$ & $0.88(0.74-1.05)$ & 0.1528 & 1.0000 \\
\hline
\end{tabular}

Corr $=$ corrected $($ Holm-Bonferroni correction); uncorr $=$ uncorrected.

Values are number of patients (\%) unless otherwise indicated.

that the use of an operating microscope in discectomy did not produce any difference in rate of wound infection, dehiscence, or hematoma. Notably, the difference in dural tear rate between macroscopic and microscopic discectomies in our study was statistically insignificant, although this intraoperative complication may be significantly undercoded by providers. Furthermore, as previously described in smaller clinical series, the length of stay was significantly shorter in our microscopic discectomy cohort than in the macroscopic discectomy cohort. Interestingly, a higher proportion of patients suffered a DVT in the macroscopic group, which may be an indirect phenomenon related to longer incisions, with more muscular, bony, and ligamentous disruption, and decreased postoperative mobilization. The rate of revision was also significantly lower in favor of microscopic discectomy.
The question remains whether use of the microscope is cost-effective. In our study, hospital payments were significantly higher in the macroscopic discectomy groupby an average of $\$ 4569$ per index procedure. Despite its equipment and facility cost, utilization of the microscope saves money, decreases hospital stay by $20 \%$, and possibly reduces reoperation rates. It is important to note that multiple payers including Medicare currently do not allow use of the operating microscope to be billed with codes for lumbar decompression or discectomy. The results from this study, however, suggest that the use of the operating microscope during lumbar discectomy may improve outcomes, reduce costs, and thus substantially improve the value provided by the procedure.

Several limitations to our study should be considered to help place these results in appropriate context. First is the

TABLE 4. Thirty-day outcomes and costs

\begin{tabular}{|c|c|c|c|c|c|c|}
\hline \multirow[b]{2}{*}{ Variable } & \multicolumn{2}{|c|}{ Discectomy Group } & \multicolumn{2}{|c|}{ Btwn-Groups Difference } & \multirow[b]{2}{*}{ OR $(95 \% \mathrm{Cl})$} & \multirow{2}{*}{$\begin{array}{c}\text { Matched } \\
\text { p Value }\end{array}$} \\
\hline & Macroscopic & Microscopic & Abs & $\%$ & & \\
\hline LOS in no. of nights, mean (SD) & $2.13(2.13)$ & $1.83(1.69)$ & 0.29 & -13.8 & & $<0.0001$ \\
\hline \multicolumn{7}{|l|}{ Payments in $\$$, median (IQR) } \\
\hline Hospital & $19,490(6599-22,440)$ & $14,921(6194-15,695)$ & 4569 & -23.4 & & $<0.0001$ \\
\hline Physician & 3469 (1250-3915) & $3485(1396-3448)$ & 16 & 0.5 & & 0.8060 \\
\hline Total & $25,109(9376-29,093)$ & $20,383(9307-22,279)$ & 4727 & -18.8 & & $<0.0001$ \\
\hline Readmissions & $871(3.9)$ & $392(3.5)$ & & & $0.90(0.79-1.01)$ & 0.0828 \\
\hline Revisions & $1965(8.8)$ & 907 (8.1) & & & $0.92(0.84-1.00)$ & 0.0366 \\
\hline \multicolumn{7}{|l|}{ Discharge status } \\
\hline Home & $19,166(85.8)$ & $10,059(90.0)$ & & & $1.50(1.39-1.61)$ & $<0.0001$ \\
\hline Other & $3173(14.2)$ & $1113(10.0)$ & & & $0.67(0.62-0.72)$ & $<0.0001$ \\
\hline
\end{tabular}

Abs = absolute; LOS = length of stay.

Values are number of patients (\%) unless otherwise indicated. 
question of whether the use of minimally invasive technologies (e.g., the use of a tubular retractor) may be a confounding factor. It is possible that the microscope group contains a significantly higher proportion of patients who underwent minimally invasive discectomies and that the apparent advantages of microscope use are in fact a reflection of minimally invasive surgery. This possibility should be considered, but there now exists a significant body of literature demonstrating broadly similar outcomes for minimally invasive discectomy and open discectomy. ${ }^{13}$ Second, since the data are derived from a payer database there may be errors in the data set from miscoding of diagnoses and procedures. The relatively low rate of dural tears in this study $(0.1 \%-0.2 \%$, significantly lower than published clinical series) suggests that such undercoding be the case in this instance. Moreover, it is possible that providers do not code for microscope use, knowing that it is not a reimbursable entity. Our analysis was restricted to those patients with continuous enrollment in the insurance system, and thus any reoperations would be robustly captured. In general, by comparing outcomes between groups, the potential for "noise" from such errors is likely to be offset by the large cohort size. In addition, we have utilized propensity matching to normalize differences in demographics and comorbidities between cohorts. Finally, this study is limited to outcomes recorded in the original data set and as such does not include other potential confounding factors such as radiographic and physical examination findings and more detailed long-term follow-up.

\section{Conclusions}

The present study suggests that the use of the operating microscope during lumbar discectomy is associated with a reduced length of stay, a lower DVT rate, a reduced reoperation rate, and decreased overall hospital costs. Use of the operating microscope may therefore lead to improved outcomes, reduced costs, and better value for patients undergoing lumbar discectomy.

\section{References}

1. Best MJ, Buller LT, Eismont FJ: National trends in ambulatory surgery for intervertebral disc disorders and spinal stenosis: a 12-year analysis of the national surveys of ambulatory surgery. Spine (Phila Pa 1976) 40:1703-1711, 2015

2. Caspar W: A new surgical procedure for lumbar disc herniation causing less tissue damage through a microsurgical approach, in Wüllenweber R, Brock M, Hamer J, et al (eds): Lumbar Disc Adult Hydrocephalus. Advances in Neurosurgery, Vol 4. Berlin: Springer, 1977, pp 74-80

3. Cenic A, Kachur E: Lumbar discectomy: a national survey of neurosurgeons and literature review. Can J Neurol Sci 36:196-200, 2009

4. Henriksen L, Schmidt K, Eskesen V, Jantzen E: A controlled study of microsurgical versus standard lumbar discectomy. Br J Neurosurg 10:289-293, 1996

5. Jacobs WCH, Arts MP, van Tulder MW, Rubinstein SM, van Middelkoop M, Ostelo RW, et al: Surgical techniques for sciatica due to herniated disc, a systematic review. Eur Spine J 21:2232-2251, 2012
6. Kahanovitz N, Viola K, Muculloch J: Limited surgical discectomy and microdiscectomy. A clinical comparison. Spine (Phila Pa 1976) 14:79-81, 1989

7. Katayama Y, Matsuyama Y, Yoshihara H, Sakai Y, Nakamura $\mathrm{H}$, Nakashima S, et al: Comparison of surgical outcomes between macro discectomy and micro discectomy for lumbar disc herniation: a prospective randomized study with surgery performed by the same spine surgeon. J Spinal Disord Tech 19:344-347, 2006

8. Koebbe CJ, Maroon JC, Abla A, El-Kadi H, Bost J: Lumbar microdiscectomy: a historical perspective and current technical considerations. Neurosurg Focus 13(2):E3, 2002

9. Kumar SS, Mourkus H, Farrar G, Yellu S, Bommireddy R: Magnifying loupes versus microscope for microdiscectomy and microdecompression. J Spinal Disord Tech 25:E235E239, 2012

10. Murphy ME, Hakim JS, Kerezoudis P, Alvi MA, Ubl DS, Habermann EB, et al: Micro vs. macrodiscectomy: Does use of the microscope reduce complication rates? Clin Neurol Neurosurg 152:28-33, 2017

11. Porchet F, Bartanusz V, Kleinstueck FS, Lattig F, Jeszenszky D, Grob D, et al: Microdiscectomy compared with standard discectomy: an old problem revisited with new outcome measures within the framework of a spine surgical registry. Eur Spine J 18 (Suppl 3):360-366, 2009

12. Schmid SL, Wechsler C, Farshad M, Antoniadis A, Ulrich $\mathrm{NH}$, Min K, et al: Surgery for lumbar disc herniation: Analysis of 500 consecutive patients treated in an interdisciplinary spine centre. J Clin Neurosci 27:40-43, 2016

13. Shriver MF, Xie JJ, Tye EY, Rosenbaum BP, Kshettry VR, Benzel EC, et al: Lumbar microdiscectomy complication rates: a systematic review and meta-analysis. Neurosurg Focus 39(4):E6, 2015

14. Türeyen K: One-level one-sided lumbar disc surgery with and without microscopic assistance: 1-year outcome in 114 consecutive patients. J Neurosurg 99 (3 Suppl):247-250, 2003

15. Williams RW: Microlumbar discectomy: a conservative surgical approach to the virgin herniated lumbar disc. Spine (Phila Pa 1976) 3:175-182, 1978

16. Yaşargil MG: Microsurgical operation of herniated lumbar disc, in Wüllenweber R, Brock M, Hamer J, et al (eds): Lumbar Disc Adult Hydrocephalus. Advances in Neurosurgery, Vol 4. Berlin: Springer, 1977, p 81

\section{Disclosures}

The authors report no conflict of interest concerning the materials or methods used in this study or the findings specified in this paper.

\section{Author Contributions}

Conception and design: all authors. Acquisition of data: all authors. Analysis and interpretation of data: Pendharkar, Rezaii, Ho, Sussman, Purger, Veeravagu, Desai. Drafting the article: all authors. Critically revising the article: all authors. Reviewed submitted version of manuscript: all authors. Approved the final version of the manuscript on behalf of all authors: Pendharkar. Statistical analysis: Rezaii, Ho, Veeravagu, Desai.

\section{Correspondence}

Arjun Vivek Pendharkar: Stanford University School of Medicine, Stanford,CA. apendhar@stanford.edu. 